\title{
Células-tronco hematopoéticas em cães
}

\author{
Hematopoietic stem cells in dogs
}

\author{
Ana Paula Massae Nakage ${ }^{1}$ Aureo Evangelista Santana ${ }^{2}$
}

\section{-REVISÃO BIBLIOGRÁFICA -}

\section{RESUMO}

As células-tronco hematopoéticas promovem a reconstituição hematopoética e de outros tecidos, estando presentes no embrião, sangue periférico, medula óssea e sangue do cordão umbilical. Os modelos experimentais de célulastronco em cães têm propiciado informações relevantes para transplantes de células-tronco em humanos. A capacidade de reconstituição hematopoética e da plasticidade das célulastronco de cães permite o emprego do modelo canino em várias propostas científicas e terapêuticas, que propiciam informações pré-clínicas ao homem. $O$ objetivo desta revisão bibliográfica é relatar a importância das células-tronco hematopoéticas de cães, sendo que a sua principal aplicação clínica é o transplante das células-tronco.

Palavras-chave: células-tronco hematopoéticas, citometria de fluxo, cães.

\section{ABSTRACT}

Stem cells provide hematopoietic and other tissues reconstitution and are present in the embryo, peripheral blood, bone marrow and umbilical cord blood. The experimental models of stem cells in dogs provide important information for stem cells transplants in humans. Their main clinical application is the stem cell transplant. The hematopoietic reconstitution and plasticity capacity of dog stem cells. Allow its use as stem cell model for therapeutic and scientific studies thus giving importat information in human pre clinical trials with stem cell. The goal of this literature review is relate the importance of canine hematopoietic stem cells.

Key words: hematopoietic stem cell, flow cytometry, dogs.

\section{INTRODUÇÃO}

A crescente abordagem das células-tronco na área científica e na mídia tem ocorrido devido à capacidade de reconstituição hematopoética e, principalmente, à característica de plasticidade das células-tronco, que permite a diferenciação destas em células de diversos tecidos, tais como, fígado, sistema nervoso central, rins, pâncreas, pulmões, pele, trato gastrintestinal, coração e músculo esquelético (HERZOG et al., 2003).

O objetivo desta revisão bibliográfica é relatar a importância das células-tronco hematopoéticas de cães que podem ser identificadas pela citometria de fluxo e têm capacidade de reconstituição hematopoética após transplantes de células-tronco. Além disso, permite o emprego do modelo canino em várias propostas experimentais e terapêuticas sobre célulastronco, que propiciam informações pré-clínicas ao homem.

\section{Hematopoese}

A hematopoese ou hemopoiese (hemato ou hemo significa sangue, poiesis significa fazer) é realizada no sistema hematopoético, o qual é constituído por células-tronco hematopoéticas (CTH), células precursoras, células sangüíneas

${ }^{1}$ Curso de Pós-graduação em Medicina Veterinária, Área de Concentração em Clínica Médica Veterinária, Faculdade de Ciências Agrárias e Veterinárias (FCAV), Universidade Estadual Paulista (Unesp). Campus de Jaboticabal, São Paulo, Brasil. Av. João Fiúsa, 1757, apto 12, 14024-250, Ribeirão Preto, São Paulo, Brasil. Autor para correspondência. E - mail: apnkg@ hotmail.com. ${ }^{2}$ FCAV, Unesp, Campus de Jaboticabal, São Paulo, Brasil 
morfofuncionalmente maduras e tecido de sustentação da hematopoese (microambiente hematopoético), localizado nas cavidades medulares de ossos chatos e longos, baço, fígado, linfonodos e timo. O sistema hematopoético é uma rede integrada de células que inicia o ciclo contínuo de diferenciação de uma pequena população de $\mathrm{CTH}$, que são pluripotentes, e que dão origem a todas as células heterogêneas funcionais do sangue e do sistema imune, fundamentando a teoria monofilética da origem do sangue (GASPER, 2000).

Biologia e plasticidade das células-tronco

A CTH tem origem mesenquimal e, durante o período de vida intra-uterino, está presente no saco vitelino embrionário e, posteriormente, desloca-se por via hematógena para o fígado, baço, linfonodos e timo fetal. Na metade do período de vida intra-uterino, a hematopoese passa a ocorrer na medula óssea, que se torna o principal sítio hematopoético no final da gestação até a vida adulta (JAIN, 1986). As CTH são as únicas células do sistema hematopoético que exibem potencial proliferativo extensivo e capacidade de se diferenciar em todas as células do sistema linfohematopoético continuamente até a morte (GASPER, 2000; HERZOG et al., 2003).

A maioria das CTH está na fase de repouso $\left(\mathrm{G}_{0}\right)$ do ciclo celular e há pouca atividade mitótica no compartimento das células-tronco, no qual ocorre a auto-renovação das referidas células e a manutenção da hematopoese pela proliferação clônica. Morfologicamente, as CTH assemelham-se aos pequenos linfócitos, tendo alta razão núcleocitoplasma, nucléolo proeminente e citoplasma basofílico destituído de grânulos (GASPER, 2000).

Estudos recentes em humanos têm revelado a plasticidade das células-tronco hematopoéticas, que podem se diferenciar em células não hematopoéticas de vários tecidos, incluindo células do fígado (ALISON et al., 2000), sistema nervoso central (MEZEY et al., 2000; JIN et al., 2002), rins (KALE et al., 2003), pâncreas (IANUS et al., 2003), pulmões (THEISE et al., 2002), pele (BADIAVAS et al., 2003), trato gastrintestinal (OKAMOTO et al., 2002), coração (ORLIC et al., 2001) e músculo esquelético (FERRARI et al., 1998).

Fontes de células-tronco hematopoéticas

Estudos iniciais em primatas e humanos estabeleceram que as CTH estão presentes no sangue periférico (KESSINGER et al., 1988; SIENA et al., 1989; SCHOTS et al., 1996; ARMITAGE et al., 1997; ABONOUR et al., 1998; PÉREZ-SIMON et al., 1998), parênquima hepático do embrião (FORRESTER et al., 1991; RICE et al., 1994), medula óssea (KESSINGER et al., 1988; WAGNER et al., 1992; HUANG et al., 1998) e sangue do cordão umbilical (BROXMEYER et al., 1989; GLUCKMAN et al, 1989; BROXMEYER et al., 1992; WAGNER et al., 1992; LIM et al., 1999). Vários relatos em humanos atestam que, as CTH com maior potencial proliferativo para o transplante são as células-tronco embrionárias, seguidas pelas células do cordão umbilical, medula óssea do adulto e sangue periférico (LANSDORP, 1995; REBEL et al., 1996; MAYANI \& LANSDORP, 1998; VERFAILLIE, 2002). O estudo com células-tronco embrionárias humanas é permitido no Brasil desde a aprovação da lei de biossegurança pela Câmara dos Deputados no primeiro semestre de 2005.

Em cães, a presença de células-tronco hematopoéticas tem sido observada na medula óssea (McSWEENEY et al., 1996; McSWEENEY et al., 1998; BRUNO et al., 1999; BRUNO et al., 2001; NIEMEYER et al., 2001; HARTNETT et al., 2002) e no sangue do cordão umbilical (NAKAGE et al., 2003; NAKAGE et al., 2004; NAKAGE, 2005).

Identificação e quantificação de células-tronco hematopoéticas

Estudos citomorfológicos e citoquímicos são métodos clássicos para caracterizar e classificar células hematopoéticas (JAIN, 1986), porém técnicas de imunocitoquímica e imunofenotipagem (anticorpos monoclonais) têm promovido um avanço na definição e classificação de células sangüíneas, particularmente aquelas de baixo grau de diferenciação (GRINDEM, 1996). Os anticorpos monoclonais conjugados com compostos fluorescentes, tais como o isotiocianato de fluoresceína (FITC) ou ficoeritrina (PE), podem ser incubados com as células a serem analisadas, permitindo a identificação e quantificação citofluorométrica de tais células (GRINDEM, 1996).

A citometria de fluxo é um recurso emergente na Clínica Médica Veterinária que permite uma análise rápida, objetiva e quantitativa de células em suspensão (FALDYNA et al., 2001). Alguns "Workshops" têm sido organizados com o intuito de classificar os anticorpos monoclonais com um número do $\mathrm{CD}$ correspondente à nomenclatura humana para diversos animais domésticos. Em relação aos anticorpos monoclonais que marcam os antígenos leucocitários caninos, estes foram definidos durante o "Primeiro Workshop Internacional de Antígeno Leucocitário Canino" ( $1^{\text {th }}$ CLAW - "First Canine Leukocyte Antigen Workshop"), ocorrido em Cambridge (U.K.) em 1993 (COBBOLD \& METCALFE, 1994), sendo que, alguns anticorpos monoclonais específicos para cães estão disponíveis comercialmente (BYRNE et al., 2000).

As células-tronco hematopoéticas derivadas da medula óssea, do fígado fetal, do cordão 
umbilical ou, até mesmo, do sangue periférico, podem ser identificadas com o auxílio de um anticorpo monoclonal dirigido contra o antígeno de superfície CD34 (HUSS et al., 2000). O protocolo para quantificação de $\mathrm{CD}_{34}{ }^{+}$, proposto pelo Comitê de Enumeração de Células-tronco, em 1995, foi o ISHAGE ("International Society of Hematotherapy and Graft Engineering"), por ser um método simples, rápido, sensível à citometria de fluxo e adequado à aplicação clínica (SUTHERLAND et al., 1996). No método ISHAGE, os anticorpos monoclonais $\mathrm{CD}^{4} 5^{+}$marcam todas as células nucleadas, tais como células-tronco e leucócitos (GRATAMA et al., 1998). Os anticorpos monoclonais CD34+ marcam células-tronco. Entretanto, algumas células exibem tamanho, granulosidade e fluorescência semelhantes às células $\mathrm{CD}^{2} 4^{+}$, sendo considerados eventos inespecíficos marcados com $\mathrm{CD} 45^{+} / \mathrm{IgG} 1$ (eventos controle). A contagem de células CD34+ é obtida através da subtração de eventos $\mathrm{CD}^{2} 4^{+} / \mathrm{CD} 45^{+}$dos eventos $\mathrm{CD} 45^{+} / \mathrm{IgG} 1$. O cálculo da contagem absoluta de células CD34+é realizado através da multiplicação da porcentagem de células $\mathrm{CD}^{4} 4^{+}$pelo número total de células nucleadas (contagem global de leucócitos) e o volume do sangue colhido. Este número é dividido pelo peso do paciente, resultando no número total de células CD34 $/ \mathrm{kg}$ (VENDITTI et al., 1999).

Na metodologia para enumeração de célulastronco, a utilização de fluorocromos excitáveis mais brilhantes, como a ficoeritrina (PE), é recomendada por ser mais sensível na detecção de células CD34+ (GRATAMA et al., 1998). A quantificação das célulastronco $\mathrm{CD} 34^{+}$pela citometria de fluxo nos animais domésticos é possível na espécie canina, devido à produção de anticorpos monoclonais específicos para CD34 canino por McSWEENEY et al. (1998). A marcação com anticorpo monoclonal canino CD34 e sua respectiva contagem por meio da análise no citômetro de fluxo permitem a identificação e quantificação das células-tronco na medula óssea (McSWEENEY et al., 1996; McSWEENEY et al., 1998; BRUNO et al., 1999; BRUNO et al., 2001; NIEMEYER et al., 2001; HARTNETT et al., 2002) e no sangue do cordão umbilical de cães (NAKAGE et al., 2003; NAKAGE et al., 2004; NAKAGE, 2005).

O grupo de pesquisa do laboratório de patologia clínica veterinária da Faculdade de Ciências Agrárias e Veterinárias (FCAV) da Universidade Estadual Paulista (UNESP), Câmpus de Jaboticabal (SP), constituído por docente, graduandos e pós-graduandos em medicina veterinária, tem realizado projetos científicos relacionados às células-tronco de cães desde 2000. No estudo pioneiro sobre células-tronco do sangue do cordão umbilical, NAKAGE (2005) quantificou as células-tronco do sangue do cordão umbilical de cães neonatos pela expressão do anticorpo monoclonal canino CD34 ${ }^{+}$PE (McSWEENEY et al., 1998) e pelo protocolo ISHAGE de citometria de fluxo (SUTHERLAND et al., 1996), que demonstraram ser um método simples, rápido, sensível e eficaz à avaliação de células-tronco de cães.

As células-tronco $\mathrm{CD}^{3} 4^{+}$do $\mathrm{SCU}$ de cães $\left(0,88 \times 10^{6} \mathrm{~mL}^{-1}\right)$ correspondem a $33 \%$ das células mononucleares $\left(2,61 \times 10^{6} \mathrm{~mL}^{-1}\right)$, segundo NAKAGE (2005). Na medula óssea, as células CD $34^{+}$representam, apenas, 1 a $2 \%$ dos mononucleares, porém são capazes de dar origem aos precursores de todas as linhagens hematopoéticas, evidenciando a habilidade das CTH de reconstituir a hematopoese em primatas, camundongos e cães após mielossupressão (KRAUSE et al., 1996). A proporção de células CD $34^{+}$na medula óssea da tíbia de cães jovens foi maior $(3,7 \pm 0,2 \%)$ do que no úmero $(2,8 \pm 0,2 \%)$, crista ilíaca $(1,7 \pm 0,3 \%) \mathrm{e}$ fêmur $(0,26 \pm 0,03 \%)$, sendo semelhante à proporção de CD34 ${ }^{+}$da medula óssea fetal humana (HUANG \& TERSTAPPEN, 1994; THILAGANATHAN et al., 1994; TURNER et al., 1996; GOLFIER et al., 2000).

A porcentagem média de células $\mathrm{CD} 34^{+}$é $11,09 \%$ no SCU de cães (NAKAGE, 2005), 10 a $18 \%$ na medula óssea de cães com duas a três semanas de idade e menos de 5\% na medula óssea de cães com mais de três meses de idade (SUTER et al., 2004). Portanto, a porcentagem de células CD34+ de cães declina com a idade. A alta proporção de células CD34+ também tem sido reportada na medula óssea fetal e de neonatos quando comparada à adulta (KONG et al., 1997; ALLEN \& HENSHAW, 2001).

A quantidade de células-tronco no sangue do cordão umbilical de cães $\left(3,38 \pm 2,72\right.$ células CD $34^{+}$ $\mathrm{x} 10^{6} \mathrm{~kg}^{-1}$ ) relatada por NAKAGE (2005) foi semelhante àquela obtida na medula óssea (BRUNO et al., 1999; HARTNETT et al., 2002; CREEVY et al., 2003) e no sangue periférico mobilizado (SANDMAIER et al., 1996; SANDMAIER et al., 2003) de cães adultos, sendo a quantidade recomendada $\left(1,2\right.$ a $\left.3,4 \times 10^{6} \mathrm{~kg}^{-1}\right)$, para reconstituição hematopoética em cães (GENGOZIAN, 2000).

A contagem de células $\mathrm{CD} 34^{+}$, como indicador da capacidade de reconstituição das células sangüíneas, foi proposta inicialmente por SIENA et al. (1989) e, atualmente, a quantificação de células CD34 ${ }^{+}$ pela citometria de fluxo tem sido amplamente adotada para realização de transplante de células-tronco (HUSS et al., 2000).

Aplicação clínica das células-tronco em cães

Estudos iniciais sobre transplante de células-tronco em cães como intervenção terapêutica para doenças na Medicina Veterinária foram realizados por APPELBAUM et al. (1986). Modelos experimentais 
em cães têm propiciado a obtenção de informações importantes no transplante de progenitores hematopoéticos autólogos e alogênicos, permitindo a transposição destes achados experimentais para os seres humanos (WAGNER \& STORB, 1996). O modelo canino permite melhor avaliação clínica, assim como, maiores facilidades na colheita e transplante (THOMAS, 1999). As CTH de cães revelaram-se fenotipicamente e funcionalmente semelhante às $\mathrm{CTH}$ de humanos e camundongos, indicando que o modelo canino é aplicável ao estudo de células-tronco, em humanos (KRAUSE et al., 1994; McSWEENEY et al., 1998; RATAJCZAK et al., 1998; BRUNO et al., 1999).

$O$ transplante de células-tronco hematopoéticas (TCTH) consiste na injeção intravenosa de progenitores hematopoéticos que se desenvolvem em microambientes especializados, nos quais se diferenciam, proliferam e amadurecem. Entretanto, a transferência de novas células imunológicas pode resultar na doença do enxerto contra o hospedeiro (DECH). Estudos recentes têm revelado que os transplantes autólogos e alogênicos de CTH são aqueles mais aplicáveis à medicina veterinária. O transplante autólogo envolve a remoção temporária de CTH do próprio receptor, seguida pela mielossupressão, induzida quimicamente ou radiologicamente, e reinfusão das $\mathrm{CTH}$, sendo que a técnica é simples e a ocorrência da $\mathrm{DECH}$ é rara. $\mathrm{O}$ transplante alogênico consiste na infusão de CTH de um indivíduo da mesma espécie com genoma diferente, sendo que o doador deve ser imunologicamente compatível com o receptor para evitar a DECH(GASPER \& THRALL, 2000).

O transplante de medula óssea alogênico com células $\mathrm{CD} 4^{+}$, em cães submetidos à terapia mielossupressiva com irradiação, propiciou a reconstituição hematopoética e permitiu antecipar uma função importante nos estudos pré-clínicos, em pacientes da referida espécie, envolvendo a manipulação in vitro de células progenitoras hematopoéticas (BRUNO et al., 1999).

Atualmente, o transplante de sangue periférico mobilizado é uma alternativa ao transplante de medula óssea. $\mathrm{O}$ transplante de sangue periférico mobilizado com fatores de crescimento hematopoéticos, tais como, o fator estimulante de colônia granulocitária ("granulocyte-colony stimulating factor" ou G-CSF) ou o fator de célula-tronco ("stem cell factor" ou SCF) permite a mobilização de células-tronco hematopoéticas da medula óssea para o sangue periférico de cães (SANDMAIER et al., 1996).

O transplante de CTH do sangue periférico e medula óssea revelam o potencial terapêutico das células-tronco em cães com linfoma (APPELBAUM et al., 1986; ABRAMS-OGG et al., 1993), doenças genéticas
(BREIDER et al., 1989; GOERNER et al., 1999; HARTNETT et al., 2002; CREEVY et al., 2003; STELZNER et al., 2003), doenças do miocárdio (KOVACIC et al., 2004; VULLIET et al., 2004), doenças vasculares (BHATTACHARYA et al., 2000; HE et al., 2003; MATSUMURA et al., 2003) e doenças do tecido ósseo (ARINZEH et al., 2003; DE KOK et al., 2003).

A quantidade de células $\mathrm{CD} 4^{+}$é proporcional à capacidade de recuperação hematopoética após o transplante de células-tronco (SIENA et al., 1989). Um importante estudo sobre transplante de medula óssea em cães, relatou que houve reconstituição hematológica após o transplante de medula óssea autólogo com 1,6 a 3,4 X10 $0^{6}$ células CD34+/ $\mathrm{kg}$ e transplante de medula óssea alogênico com 1,75 a $6,8 \times 10^{6}$ células $\mathrm{CD} 34^{+} / \mathrm{kg}$. Cães que receberam menos de $1,0 \times 10^{6} \mathrm{CD}^{+} 4^{+} / \mathrm{kg}$ apresentaram lenta recuperação da celularidade neutrofílica e plaquetária (BRUNO et al., 1999) e linfocítica (HARTNETT et al., 2002). O transplante de sangue periférico mobilizado com 4,6 x $10^{6}$ células $\mathrm{CD} 34^{+} / \mathrm{kg}$ permitiu a reconstituição hematopoética dos cães (SANDMAIER et al., 1996), sendo uma alternativa ao transplante de medula óssea, devido à facilidade na colheita e à rapidez de recuperação granulocitária e plaquetária.

\section{CONCLUSÃO}

As células-tronco de cães podem ser identificadas pela expressão citofluorométrica do anticorpo monoclonal canino $\mathrm{CD} 34^{+}$, sendo que a sua principal aplicação clínica é o transplante das célulastronco. A capacidade de reconstituição hematopoética e da plasticidade das células-tronco permite o emprego do modelo canino em várias propostas científicas e terapêuticas, que propiciam informações pré-clínicas ao homem.

\section{FONTEDEAQUISIÇÃO}

Fundação de Amparo à Pesquisa do Estado de São Paulo - FAPESP (processos 01/01017-7 e 01/01016-0).

\section{REFERÊNCIAS}

ABONOUR, R. et al. Autologous transplantation of mobilized peripheral blood $\mathrm{CD}_{3} 4^{+}$cells selected by immunomagnetic procedures in patients with multiple myeloma. Bone Marrow Transplantation, Basingstoke, v.22, n.10, p.957-963, 1998.

ABRAMS-OGG et al. Clinical and pathological findings in dogs following supralethal total body irradiation with and without infusion of autologous long-term marrow culture cells. Canadian Journal of Veterinary Research, Ottawa, v.57, n.2, p.79-88, 1993.

ALISON, M.R. et al. Hepatocytes from non-hepatic adult stem cells. Nature, London, v.406, n.6793, p.257, 2000. 
ALLEN, J.E.; HENSHAW, D.L. An in situ study of CD34(+) cells in human fetal bone marrow. British Journal of Haematology, Oxford, v.114, n.1, p.201-210, 2001

APPELBAUM, F.R. et al. Cure of malignant lymphoma in dogs with peripheral blood stem cell transplantation. Transplantation, Baltimore, v.42, n.1, p.19-22, 1986.

ARINZEH, T.L. et al. Allogeneic mesenchymal stem cells regenerate bone in a critical-sized canine segmental defect. Journal of Bone and Joint Surgery. American Volume, Boston, v.85-A, n.10, p.1927-1935, 2003.

ARMITAGE, S. et al. CD34 counts to predict the adequate collection of peripheral blood progenitor cells. Bone Marrow Transplantation, Basingstoke, v.20, n.7, p.587-591, 1997.

BADIAVAS, E.V. et al. Participation of bone marrow derived cells in cutaneous wound healing. Journal of Cellular Physiology, Philadelphia, v.196, n.2, p.245-250, 2003.

BHATTACHARYA, V. et al. Enhanced endothelization and microvessel formation in polyester grafts seeded with $\mathrm{CD} 34^{+}$ bone marrow cells. Blood, New York, v.95, n.2, p.581-585, 2000 .

BREIDER, M.A. et al. Long term effects of bone marrow transplantation in dogs with mucopolysaccharidosis. American Journal of Pathology, Philadelphia, v.134, n.3, p.677-692, 1989.

BROXMEYER, H.E. et al. Human umbilical cord blood as a potential source of transplantable hematopoietic stem/ progenitor cells. Proceedings of the National Academy of Sciences of the United States of America, Washington, v.86, n.10, p.3828-3832, 1989.

BROXMEYER, H.E. et al. Growth characteristics and expansion of human umbilical cord blood and estimation of its potentia for transplantation in adults. Proceedings of the National Academy of Sciences of the United States of America, Washington, v.89, n.9, p.4109-4113, 1992

BRUNO, B. et al. CD $34^{+}$selected bone marrow grafts are radioprotective and establish mixed chimerism in dogs given high dose total body irradiation. Transplantation, Baltimore, v.68, n.3, p.338-344, 1999.

BRUNO, B. et al. Purified canine CD34+Lin- marrow cells transduced with retroviral vectors give rise to long-term multilineage hematopoiesis. Biology and Blood Marrow Transplantation, Baltimore, v.7, n.10, p.543-551, 2001.

BYRNE, K.M. et al. A standardized gating technique for the generation of flow cytometry data for normal canine and normal feline blood lymphocytes. Veterinary Immunology and Immunopathology, Amsterdam, v.73, n.2, p.167-182, 2000

COBBOLD, S.; METCALFE, S. Monoclonal antibodies that define canine homologues of human $\mathrm{CD}$ antigens: summary of the first International Canine Leukocyte Antigen Workshop (CLAW). Tissue Antigens, Copenhagen, v.43, n.3, p.137154, 1994.

CREEVY, K.E. et al. Mixed chimeric hematopoietic stem cell transplant reverses the disease phenotype in canine leukocyte adhesion deficiency. Veterinary Immunology and Immunopathology, Amsterdam, v.95, n.3-4, p.113-121, 2003 .
DE KOK, I.J. et al. Investigation of allogeneic mesenchymal stem cell-based alveolar bone formation: preliminary findings. Clinical Oral Implants Research, Copenhagen, v.14, n.4 p.481-489, 2003.

FALDYNA, M. et al. Lymphocyte subsets in peripheral blood of dogs - a flow cytometric study. Veterinary Immunology and Immunopathology, Amsterdam, v.82, n.1-2, p.23-37, 2001 .

FERRARI, G. et al. Muscle regeneration by bone marrowderived myogenic progenitors. Science, Washington, v.279, n.5356, p.1528-1530, 1998.

FORRESTER, L.M. et al. Long-term reconstitution of the mouse hematopoietic system by embryonic stem cell-derived fetal liver. Proceedings of the National Academy of Sciences of the United States of America, Washington, v.88, n.17, p.7514-7517, 1991

GASPER, P.W. The hemopoietic system. In: FELDMAN, B.F. et al. Schalm's veterinary hematology. Philadelphia: Williams \& Wilkins, 2000. Cap.11, p.63-68.

GASPER, P.W.; THRALL, M.A. Hemopoietic stem cell transplantation. In: FELDMAN, B.F. et al. Schalm's veterinary hematology. Philadelphia: Williams \& Wilkins, 2000. Cap.17. p.97-101

GENGOZIAN, N. Identification and isolation of hemopoietic progenitors. In: FELDMAN, B.F. et al. Schalm's veterinary hematology. Philadelphia: Williams \& Wilkins, 2000. Cap.16, p.91-96.

GLUCKMAN, E. et al. Hematopoietic reconstitution in patient with Fanconi's anemia by means of umbilical-cord blood from an HLA-identical sibling. New England Journal of Medicine, Waltham, v.321, n.17, p.1174-1178, 1989.

GOERNER, M. et al. The use of granulocyte colony-stimulating factor during retroviral transduction on fibronectin fragment CH-296 enhances gene transfer into hematopoietic repopulating cells in dogs. Blood, New York, v.94, n.7, p.22872292, 1999

GOLFIER, F. et al. Fetal bone marrow as a source of stem cells for in utero or postnatal transplantation. British Journal of Haematology, Oxford, v.109, n.1, p.173-181, 2000.

GRATAMA, J.W. et al. Flow cytometry enumeration of CD34 hematopoietic stem and progenitor cells. Cytometry, New York, v.34, n.3, p.128-142, 1998.

GRINDEM, C.B. Blood cell markers. Veterinary Clinics of North America: Small Animal Practice, Philadelphia, v.26, n.5, p.1043-1065, 1996.

HARTNETT, B.J. et al. Transplantation of X-linked sever combined immunodeficient dogs with $\mathrm{CD} 34^{+}$bone marrow cells. Biology of Blood and Marrow Transplantation, Charlottesville, v.8, n.4, p.188-197, 2002.

HE, H. et al. Canine endothelial progenitor cell-lined hybrid vascular graft with nonthrombogenic potential. Journal of Thoracic and Cardiovascular Surgery, St. Louis, v.126, n.2, p.455-464, 2003

HERZOG, E.L. et al. Plasticity of marrow-derived stem cells. Blood, New York, v.102, n.10, p.3483-3493, 2003. 